\title{
Apreciaciones sobre el concepto de imaginarios sociales.
}

\author{
Some considerations about social imaginaries concept.
}

\author{
Juan-Luis Pintos de Cea - Naharro ${ }^{1}$ \\ Pintos de C. Juan L. miradas $\mathrm{N}^{\circ} 13$ - 2015. ISSN: 0122 994X Págs 150 - 159 \\ Recepción: Mayo 7 de 2015 \\ Aprobación: Octubre 6 de 2015 \\ Publicación: Diciembre 17 de 2015
}

\section{Resumen}

Han pasado suficientes años de uso del término "Imaginarios" para que intentemos una clarificación provisional de tal concepto. ¿Es realmente "un concepto”? ¿Hay diferencias importantes en su uso? ¿No corremos el peligro de ontologizar ${ }^{1}$ tratando de establecer una definición "doctrinal" que permita distinguir ortodoxias y heterodoxias? Quizás haya que esperar más tiempo y dejar para futuros investigadores un estudio más completo y exhaustivo. Pero a día de hoy, 2014, quiero aportar a esos futuros investigadores algunas reflexiones que puedan ayudar a aclararse en este campo que empieza ya a producir nuevos frutos. Se trata de aportar algunas precisiones sobre la cuestión de entender lo que hacemos, lo que nos rodea y por qué, necesariamente tenemos que enfrentarnos con los procesos múltiples de construcción de la realidad.

Palabras Clave: Imaginarios sociales, representaciones sociales, cibernética, ontología, realidad, comunicación.

\begin{abstract}
We have used the concept of imaginaries during a lot of time. Then we have to clarify this concept. ¿Is it really a concept? ¿Are there important differences around it use? ¿Would became this concept in something ontolical if we try to construct a "doctrinal" definition? Perhaps, we will have to wait a lot of time; then the future researchers would make more profound investigations relative this concept. But now, in 2014, i want to contribute in this area; especially in relation whit the following possibility: to understand what we do, to understand all the things and proccesses that go around us.
\end{abstract}

Key Word: Social imaginaries, social representations, cybernetics, ontology, reality, communication.

1 Doctor en Filosofía y Letras por la Universidad de Madrid. Actualmente es Profesor Emérito del Departamento de Sociología de la Universidad de Santiago en la Facultad de CC.Políticas y Sociales. Coordinador GCEIS («Grupo Compostela de Estudios sobre Imaginarios Sociales») juanluis.pintos@usc.es 


\section{Introducción}

Hay que señalar que el momento intelectual o de pensamiento en el que nos movemos no propicia ni la adscripción a campos ideológicos nítidos, ni la inclusión en escuelas de pensamiento definidas, ni una respuesta precisa a la exigencia cartesiana de "ideas claras y distintas". Más bien, en esta disolución de la llamada "posmodernidad", nos encontramos como posiciones más frecuentes o bien un intento de vuelta al pasado de radicalismos dogmáticos y cerrados de ambos extremos del abanico político tradicional al que se incorporan veladamente formas tradicionales de violencia espiritual y/o física, o bien determinadas interpretaciones de la complejidad como máscara de la indecisión y la pereza de pensar y actuar en lo social y lo político. A lo que se suma una creciente posición de vinculación normativa de las religiones o las morales con las decisiones propiamente políticas.

El vehículo principal de esta forma de comunicación y reflexión es el ámbito general de los "Media" (incluido el espacio interindividual que facilitan determinadas aplicaciones informáticas, que algunos denominan "redes sociales") y sus actores principales son los profesionales del periodismo. Profesionales que están sustituyendo de hecho a los discursos especiales de otras perspectivas específicas que hasta ahora tomaban parte en la construcción de la información en la sociedad: historiadores, sociólogos, teólogos, filósofos y otros "expertos" en campos determinados de las ciencias; físicos, matemáticos, químicos, biólogos, etc. Los únicos que siguen apareciendo en los medios de estos profesionales suelen ser o economistas o psicólogos, cuya función principal es apoyar "científicamente" el discurso previamente elaborado de los periodistas.
En épocas anteriores los periodistas no tenían formación académica (universitaria) específica. Se partía de que era el "testigo directo" de lo que sucedía: en la calle, en el Parlamento, en las catástrofes o en la vida cotidiana de las personas, en lugares cercanos o lejanos. Era "el que estaba allí" y contaba lo que había visto. Era el primer agente "globalizador" de la información que se suponía interesaba a los lectores (no muchos, ni identificables con los "ciudadanos"). Eso sí su fuerte era la capacidad narrativa y la forma de comunicar escrita. Eran "observadores" cuya cualidad principal o exigencia profesional era la "objetividad" lo que equivalía a poner entre paréntesis su propia ideología.

Esta función ha ido cambiando en los últimos años. En el largo plazo, desde finales del XIX, se comenzó a decidir lo que tenía que informarse, independientemente de lo que el periodista observase. El hundimiento del Maine (La Habana, 1898) y la noticia del hecho publicada en los periódicos de William Randolph Hearst es el punto de arranque de esta refuncionalización de los medios. La transformación radica en la sustitución del "público" por la "audiencia". Aparece (se presenta como "realidad") lo que vende, lo que no vende "no existe". La complejidad inherente al sistema mediático se simplifica con esquemas de comunicación abstractos o consignas estigmatizadoras.

El problema central que vinculo con mi posición en la definición de los imaginarios sociales es el de la construcción social de la realidad. No me interesan las discusiones metafísicas acerca de lo que sea "realidad" o "la realidad" propuestas a lo largo de la historia de la filosofía. Sí me interesa lo que los individuos creen y aceptan operativamente que sea "realidad". El impulso más importante para tratar de 
elaborar una teoría de los imaginarios me vino de Niklas Luhmann y en particular de un breve libro titulado "La realidad de los medios de masas" cuya primera frase dice: "Lo que sabemos sobre nuestra sociedad, incluso sobre el mundo en el que vivimos y conocemos, lo conocemos a través de los medios de masas". que cierra el libro: “¿Cómo es posible que aceptemos informaciones sobre el mundo y sobre la sociedad como informaciones sobre la realidad, cuando se sabe, cómo se producen?". Esa pregunta incisiva, acuciante me metió en un camino en el que casi todas mis lecturas filosóficas y sociológicas se vieron necesitadas de un replanteamiento. No era una nueva teoría, era la puesta en cuestión de muchas teorías. Y así comencé a reflexionar de nuevo sobre la sociología que pensaba y que practicaba y a tratar de encontrar respuesta a esa pregunta sobre ¿cómo podemos creer en una realidad si sabemos cómo se produce? En otro momento intentaré reconstruir los pasos dados en ese camino. Ahora me ocuparé de referirme a los diferentes usos $\mathrm{y}$ formas en los que se ha abordado el tema de los imaginarios y sus propuestas de definición.

\section{Resultados y discusión}

\section{Concepciones más o menos "vulgares"}

Utilizo el término "vulgar" no en sentido peyorativo o despectivo. Quizás habría que hablar de los espectadores de la Caverna, o de los "Idola fori", o del "común de los mortales". Se trataría del hombre (y mujer) común, el que forma y transforma la comunidad en la que están juntos los iguales, no el "hombre medio", esa abstracción estadística tan utilizada en los Media, lo mismo que la inevitable "clase media".

Desde esa perspectiva cognitiva el término "Imaginarios" se interpreta habitualmente como algo perteneciente al campo semántico de la ficción. Los imaginarios serían producto de la imaginación (que Teresa de Ávila definía como "la loca de la casa"). Por tanto, lo opuesto a la realidad y al "realismo" (lo mismo literario que pictórico o filosófico). También se podría entender como algo vinculado a la invención o a la creatividad. Esta connotación vincularía los estudios sobre imaginarios con una capacidad propia de los individuos "creativos" y sus formas de comunicación con la sociedad a través de imágenes, poesía, inventos, etc. En los últimos tiempos se suele asociar esta creatividad a la producción de programas informáticos en digitalizaciones, juegos, performances, etc.

Hay otra versión que se suele expresar con frases como: "lo que la gente se imagina, cree, piensa, espera o vincula su acción a determinados objetivos". De un modo más académico esta versión vendría formulada en términos cercanos a las corrientes fenomenológicas. Estas refieren preferentemente el término de imaginarios a los sujetos hablantes o que perciben la realidad de maneras específicas. Habría que ampliar analíticamente esta observación, porque tiene que ver con metodologías de análisis de la vida cotidiana que representan las reflexiones de autores de elevado interés ${ }^{3}$

\section{Concepciones vinculadas a diferentes marxismos}

Si bien la figura de referencia inevitable es Cornelius Castoriadis y su obra básica publicada en 1975 "La institución imaginaria de la sociedad", en mi experiencia particular fue un párrafo del capítulo primero de "El Capital" de Karl Marx dedicado al fetichismo de la mercancía el que me abrió los ojos al problema: 
"Los hombres no relacionan entre sí los productos de su trabajo como valores porque estos objetos les parezcan envolturas simplemente materiales de un trabajo humano igual. Es al revés. Al equiparar unos con otros en el cambio, como valores, sus diversos productos, lo que hacen es equiparar entre sí sus diversos trabajos, como modalidades de trabajo humano. No lo saben, pero lo hacen. Por tanto, el valor no lleva escrito en la frente lo que es. Lejos de ello, convierte a todos los productos del trabajo en jeroglíficos sociales."

Estos "jeroglíficos sociales", este "secreto", este "no saber pero hacer" es una forma específica de trabajo sociológico. Marx lo inauguró haciendo girar todas sus observaciones de la sociedad y el sistema desde una única perspectiva: la economía. $\mathrm{Su}$ éxito histórico produjo efectos que él mismo no podía prever y que si hubiera llegado a conocerlos seguramente rechazaría.

Algunas de mis formulaciones primeras seguían esa orientación:

"La orientación primaria de mi investigación se centra en la consideración de los Imaginarios Sociales como constructores del orden social. La práctica de la investigación sociológica me ha llevado a la conclusión de que la mayor dificultad con la que nos encontramos en el ejercicio de este oficio se podría resumir en una frase de larga tradición: "Hacer visible la invisibilidad social”.

Hoy no sigo manteniendo ese proyecto, como expondré más adelante, pero no reniego de él. En un momento de mi vida lo consideré como posible y deseable. Hoy me percibo en otra posición.

Posteriormente a mis lecturas de Marx me incliné por autores que parecían actualizar ese pensamiento y adaptarlo a otra situación histórica. Me refiero fundamentalmente a Ernst Bloch, Antonio Gramsci y Cornelius Castoríadis.

En la obra fundamental del germano, " $E l$ Principio Esperanza", muy poco leído en nuestro ámbito lingüístico a pesar de las buenas traducciones publicadas, hay una investigación elaborada histórica y culturalmente del conjunto pregnante que encierra el término "Utopía". De ese universo tomé un pequeño fragmento del capítulo dedicado a la conciencia anticipadora y a los sueños nocturnos y diurnos:

"De modo distinto al del sueño nocturno esboza el diurno en el aire configuraciones elegibles $y$ repetibles, puede fantasear $\mathrm{y}$ desbarrar, pero también reflexionar y planificar. Depende de modo ocioso (puede sin embargo emparentarse con las Musas y con Minerva) de pensamientos que tienen que ver con lo político, lo artístico, lo científico. El sueño diurno puede proporcionar ideas que exigen no interpretación sino elaboración, construye castillos en el aire también como imágenes proyectivas y no siempre ficticias" Bloch, E., [1959], Das Prinzip Hoffnung (Frankfurt, Suhrkamp, 1969), I, p.96"

Esta distinción entre "ficticio" y "proyectivo" me dio otra clave para afinar mi concepto de imaginarios sociales.

Para no extenderme más en la descripción de este tipo de definiciones, únicamente añadiré que el concepto de "Hegemonía" de 
Gramsci me llevó a entender la revolución como un proceso dilatado en el tiempo (no el "grand jour", ni el asalto al Palacio de invierno, ni la salida al balcón de la Puerta del Sol en la segunda república, que en los años 70 tenían gran prestigio político).

Una nota sobre un autor que surge siempre que se habla o escribe sobre imaginarios sociales: Cornelius Castoríadis. Su agitada biografía política, su crítica al capitalismo y posteriormente al mismo marxismo, su afianzamiento en el psicoanálisis y su gran aliento metafísico y ontológico no me parecían camino transitable para una orientación claramente sociológica de la temática de imaginarios. Sin embargo, su permanencia y su influencia son enormes, incluso en nuestro país. Actualmente es el autor de referencia del tema.

Desde esta perspectiva se han creado dos imaginarios potentes y de gran alcance político, no así económico. Me refiero al imaginario "Capitalismo", "Sistema capitalista", "Neoliberalismo", etc. Han sabido conjugar unos procesos analíticos rigurosos en el campo económico con unas formas políticas ajenas a las democráticas (las denominaciones de "Repúblicas democráticas o populares" de determinados regímenes de posguerra o actuales han llegado a convencer a millones de personas de muy diferentes culturas y continentes). Junto a ese imaginario de tipo sistémico ha tenido un gran auge y seguimiento el imaginario de la "Revolución", hoy un tanto devaluado por los usos ajenos a la política y por el fracaso de determinados procesos denominados "revolucionarios".

\section{Concepciones vinculadas a la semántica y la hermenéutica}

En mi recorrido personal en busca de aclararme sobre la relevancia teórica y operativa de los imaginarios sociales me encontré con la "aventura semiológica" de Roland Barthes. No voy a resumir aquí sus planteamientos ni su evolución teórica, ni sus posiciones políticas, cercanas y críticas con el marxismo. Ni sus diferencias y semejanzas con la corriente angloamericana de la semiótica. Lo que me interesó desde un principio fue su inquietud práctica pluridisciplinar y el eje sentido y significado como piedra angular de los discursos. Y sobre todo sus propuestas metodológicas del análisis de textos y de los análisis retóricos de las imágenes. $\mathrm{Me}$ interesaban sus campos de análisis: medios, publicidad, arte, objetos cotidianos, etc.

A partir de ahí comencé a vincular los "campos semánticos" con la teoría y la práctica de los imaginarios. Las cuestiones como "¿Quién habla?”, “¿Desde dónde se habla?" convertidas posteriormente en la necesidad de precisar los mecanismos de observación y la necesaria distinción entre el primer y segundo orden de la observación, como veremos más adelante, me obligaron a plantearme el "marco social del conocimiento". El sentido no se identificaba con un sentimiento subjetivo sino que era lo que Max Weber consideraba el arranque de toda posible reflexión sociológica: "el sentido mentado de la acción"; una acción empieza a ser social cuando tiene sentido para otro. De ahí la insuficiencia del análisis semiológico puro para una comprensión sociológica de lo que sucede.

Por eso en una etapa intermedia de la elaboración de mi teoría utilicé la expresión "representaciones sociales". Me parecía que el trabajo de observación sociológico tenía que ejercitarse sobre objetos definidos. Una vez más la protesta contra la "Caverna"; una vez más el objeto como resistencia; una vez más las formas tradicionales de pensamiento y sus distinciones y dicotomías (sujeto/objeto, materialismo/ idealismo, realidad/ficción). 
Algo tenía que estar ahí para ser analizado, observado, medido...70 años después de Plank, Bohr y Heisenberg. De ahí el uso del término "representaciones", ya que el imaginario sería la fuente o el origen de las imágenes que podemos percibir mediante instrumentos sensitivos. Es importante señalar que en este campo se produce un enorme número de reflexiones filosóficas, antropológicas, comunicativas y sociológicas porque implican procesos complejos tales como la percepción y la comunicación, el lenguaje (oral, escrito, corporal), la hermenéutica de los significados y la no menos extensa investigación sobre los símbolos.

\section{Conclusiones}

\section{Concepción sistémica y sociocibernética.}

Parte del análisis de la "complejidad" y de la decisión como selección de posibilidades. Utiliza como eje diferenciador el código comunicativo "relevancia/opacidad". Pasemos a desarrollar con cierta amplitud esta perspectiva desde la que propondremos la definición de imaginarios sociales que hoy en día consideramos apropiada teórica y operativamente.

Las sociedades actuales, estos espacios y tiempos caóticos en los que creemos vivir, hay que pensarlas bajo el concepto de "policontexturalidad". Vivimos en sociedades policontexturales de elevada complejidad. Vivimos en sociedades que ya no disponen de centros ni vértices como referencias únicas o totales de sentido para todos. Tenemos que enfrentarnos con situaciones de elevada complejidad y no disponemos de un repertorio de saberes que nos permitan en cada momento situarnos inequívocamente en un determinado ámbito de la realidad. Cada sistema social funcionalmente diferenciado tiene la pretensión de que su código particular puede definir la realidad de la sociedad. Pero es su misma diferencia la que los limita recíprocamente. Por eso ha adquirido una importancia excepcional el metacódigo "Inclusión/Exclusión". Cada sistema tiene que estar definiendo y delimitando constantemente el ámbito de operación funcional de su código propio; ello produce efectos de inclusión en los programas que desarrolla y de exclusión para los no afectados. Hay una tendencia actualmente a valorar positivamente los efectos de inclusión de los sistemas parciales en cuanto que la gestión de los gobiernos se reduce en muchos casos a identificar grupos de sujetos para incluirlos en sus operaciones de políticas públicas. Pero esa tendencia tiene como efecto inevitable el de excluir a otros grupos de las mismas, dado que la generalización de los factores de inclusión requieren una infinita obtención de recursos. De ahí los efectos paradójicos de los denominados "Estados del Bienestar" en un contexto de globalización de la información. Los años últimos definidos por muchas instancias sociales como de "Crisis" no han hecho más que confirmar estos procesos sociales de fondo.

El sistema social actual, funcionalmente diferenciado(Sistemas económico, político, científico, jurídico, educativo, religioso, mediático, etc.), solo puede legitimarse por el ejercicio de su función que consiste en resolver los problemas planteados por los individuos situados en su entorno. No existen los individuos para beneficio del sistema, sino el sistema se justifica beneficiando a los individuos. Estos son los que irritan a los diferentes subsistemas a través de sus exigencias y obtienen así rendimientos que responden a sus expectativas. No hay ninguna instancia que pueda definir puntual o permanentemente estas expectativas. Nadie está legitimado inicialmente para hablar en nombre de los demás (problemática histórica de la 
"salvación"). Pero los individuos aislados tienen pocas probabilidades de obtener respuesta a sus propuestas, sea la que sea su posición respectiva en el entorno del sistema.

Por esto el funcionamiento satisfactorio de los sistemas socialmente diferenciados requiere la constitución de organizaciones (de diferentes niveles de actuación, públicos, privados, locales, globales, familiares, profesionales, etc.) a través de las que se pueda evaluar la capacidad de los sistemas de satisfacer las necesidades planteadas. Las organizaciones se definen básicamente como estructuras capaces de tomar decisiones colectivas en base a las informaciones recibidas. Actúan así cibernéticamente, nunca sustantivamente o en base a principios inmutables, sino siempre vinculadas al tiempo, a través de recorridos recurrentes de los procesos sociales.

El poder ya no es, por tanto, el constitutivo propio de la política. El orden de la sociedad no se construye por la subordinación de una parte de la sociedad a otra según el modelo de la dominación, sino por la definición de realidades que puedan ser reconocidas como tales por los implicados. El mecanismo básico de construcción de esas realidades son los imaginarios sociales que nos permiten percibir algo como real a través de la articulación del código "relevancia / opacidad".

Tenemos, por tanto que proponer sobre estas bases una definición teórica y operativa de lo que denominamos imaginarios sociales, recogiendo lo que las investigaciones que hemos realizado nos han proporcionado.

Los Imaginarios sociales [1]

Están siendo [2]

Esquemas [3]

\section{Construidos socialmente [4]}

Que orientan [5]

Nuestra percepción [6]

Permiten [7]

Nuestra explicación [8]

Hacen posible [9]

Nuestra intervención [10]

En lo que en diferentes sistemas sociales [11]

\section{Sea tenido como realidad [12]}

Veamos ahora cada uno de esos elementos de la definición ampliando el significado que nosotros proponemos:

1. Los imaginarios sociales: en plural, porque las sociedades en las que vivimos son policontexturales no tienen centros ni vértices que produzcan un imaginario único ni una verdad indiscutible, ni una moral universalmente válida.

2. Están siendo: no proponemos una definición ontológica ("son") sino una evolutiva que va transformándose, adaptándose y renovándose.

3. Esquemas: en el sentido de la tercera acepción del DRAE: "Idea o concepto que alguien tiene de algo y que condiciona su comportamiento", pero no en el de "representación" (acepción 1 del DRAE). Más bien habría que pensar en la propuesta kantiana del espacio y el tiempo como esquemas a priori. No son observables ni medibles como un objeto, pero hacen posible entender muchos objetos.

4. Construidos socialmente: no construidos por los sujetos sino por las estructuras y sistemas en que esos sujetos habitan. Habría que recordar 
a Berger \& Luckmann y sus ideas sobre las sociedades como realidades objetivas (institucionalización y legitimación) y como realidades subjetivas (internalización); y también la diferencia que propone Jürgen Habermas entre "integración social" e "integración sistémica".

5. Que orientan: no son determinantes ni causantes. Orientar es una acción vinculada a la perspectiva cibernética de producir un control a través de la retroalimentación comunicativa y la recursividad. Orientar es la posibilidad de variar el rumbo de la observación y de distinguir entre la observación de primer orden (la que nos cuenta lo que ve) y la de segundo orden (la que observa a los observadores).

6. Nuestra percepción: no nuestra acción ni nuestro pensamiento. No tiene que ver con una integración ideológica en las creencias de un grupo, sino que lleva al observador a percibir determinados hechos y no otros, a enfocar la mirada hacia una determinada dirección y no en otra. Lo que es peculiar de los imaginarios es que su material propio de observación no son las imágenes sino la distinción "dentro de campo" "fuera de campo". Como lo que está fuera de campo no es observable el análisis de los imaginarios asume como punto de partida la crítica de lo observable: ¿por qué percibimos determinadas cosas, palabras, acciones, etc. y otras no? Los imaginarios se vinculan a lo empírico y sus mecanismos, no a las ideas o creencias de la gente. No pregunta ¿qué se cree la gente?, sino ¿qué sucede para que la gente se crea determinadas cosas? $\mathrm{Y}$ eso sucede un una sociedad específica que produce ciertos mecanismos que deciden acerca de la observabilidad de lo observable
7. Permiten: en el sentido de superar la coacción ideológica que obliga a ver las cosas de una determinada manera y a emplear ciertos esquemas interpretativos (como por ejemplo buscar la "culpabilidad" de alguien en algún hecho no deseable por la mayoría y poderlo establecer como causa atribuida del suceso)

\section{Nuestra explicación: no} pertenecen los imaginarios al campo de los sentimientos ni de las emociones, aunque sean elementos muy presentes y eficaces en los procesos de construcción de realidades. El análisis de esos procesos trata de establecer de un modo accesible y riguroso una explicación posible. Si bien no tienen la pretensión de proponer la explicación como "única", sino como "plausible"

9. Hacen posible: al establecer las operaciones de los mecanismos constructivos pueden ofrecer un panorama diferenciado de explicaciones que sitúen el campo de la acción en el de la selección de posibilidades. No se dejan llevar por voluntarismos capaces de imaginar sólo mundos deseados (o deseables) sino mundos posibles.

10. Nuestra intervención: específico de nuestra teoría es su voluntad de no pretenderserneutral.Lasinvestigaciones realizadas no nos permiten establecer un marco continuo de toma de decisiones que implicarían una única y permanente posición política. Nuestra pretensión es mantener nuestros análisis fuera de los ámbitos ideológicos tradicionales (izquierda, centro, derecha) y de los ámbitos "confesionales" (artísticos, religiosos, filosóficos, etc.). Pensamos no tener "la razón" pero sí "tener razones" que aportar en las sociedades basadas en la comunicación. Pero pretendemos mantener el proceso 
comunicativo fuera de los espectáculos. La comunicación se produce siempre en trayectorias abiertas y recurrentes: hay que plantear preguntas y no contentarse con las respuestas.

\section{En lo que en diferentes sistemas} sociales: No tenemos ninguna pretensión de universalidad de nuestra teoría. Más bien pensamos que proyectos, métodos, técnicas, "data mining", etc. se producen en configuraciones sociales distintas. No ha sido posible, por ejemplo, aplicar la teoría marxista de las clases sociales a países de distintas culturas o religiones, ni tampoco establecer un "modelo" único de revolución. Tener en cuenta esos fracasos teóricos, políticos y prácticos nos lleva a la conclusión de que tenemos que pensar en términos de "pluriversos" (ya no universos), de diversidad cultural (y no de multiculturalidad), de diferentes "modernidades" y diferentes formas de gestión política (no en políticas ideales que siguen un modelo único).

\section{Sea tenido como realidad: este} es el eje central de nuestra teoría. La afirmación, basada en la experiencia $\mathrm{y}$ en el análisis de que no podemos contar (en nuestra situación presente) con que la realidad sea única. Ya hace muchos años Alfred Schütz se preocupó de esta cuestión y planteó una teoría de "realidades múltiples", pero han pasado ya setenta años $\mathrm{y}$ necesita actualizaciones. No es posible desarrollar aquí nuestras perspectivas actuales pero constituirán una parte principal del libro que estamos preparando.

\section{Referencia Bibliográfica}

Baeza, M. (2008). Mundo real, mundo imaginario social. Teoría y práctica de sociología profunda. Santiago de Chile: RIL.
Barthes, R. (1994). La aventura semiológica. España: Planeta - Agostini.

Berger, P. \& Luckmann, Th. (1966). La construcción social de la realidad. España: Amorrurtu.

Beriain, J. (2005). Modernidades en disputa. España: Anthropos.

Habermas, J. (1981). Teoría de la acción comunicativa. España: Taurus. 1987.

Luhmann, N. (1991). Teoría de los sistemas sociales. México: Alianza.

Maturana, H. (1997). La objetividad: un argumento para olvidar. España: Editorial Dolmen.

Moscovici, S. (1986). Psicología Social I y II. España: Paidós.

Pintos, J. (1994). Marco sistémico y esquema conceptual. Madrid: Editorial Síntesis.

Pintos, J. (1995). Los imaginarios sociales. La nueva construcción de la realidad social. España: Sal Terrae.

Pintos, J. (1999). Apuntes para una teoría: los medios, la realidad y la alternativa local. Santiago: Lea.

Pintos, J. (2000). A educación en Perspectiva. Revista Realidad (1) 689 - 699.

Pintos, J. (2000). Construyendo realidad (es): Los imaginarios sociales. Revista Realidad. (2) $7-25$.

Pintos, J. (2000). Los imaginarios sociales del delito. La construcción social del delito por medio de las películas (1930 - 1999). Revista Realidad. (3). $35-40$.

Pintos, J. (2000). Mas allá de la sociología. La construcción de la plausibilidad a través de los imaginarios sociales. España: Santos Editores.

Pintos, J. (2011). La distinción política / moral como exigencia de la organización plural de la convivencia. Revista: Pensar radicalmente a humanidade. (40) $391-406$. 
Ricoeur, P. (1965). De l'interprétation. Essai sur Freud. Paris: Seuil.

Searle, J. (1977). La construcción de la realidad social. España: Paidos.

Serna, A. J. (2007). Ontologías Alternativas. España: Editorial Anthropos.

Taylor Ch. (2004). Imaginarios sociales modernos. España: Paidós.

Von Foerster, H. (1991). Las semillas de la cibernética. Obras escogidas. España: Gedisa.

Westdeutscher, V. (1996). Die Realität der Massenmedien. España: Anthropos.

Williams, R. (1980). Marxismo y literatura. España: Península.

\section{Notas al lector}

1 Tengo que referirme a las obras del filósofo y amigo colombiano Julián Serna Arango y en particular a Ontologías alternativas (Anthropos, 2007). Trabaja en la Universidad Tecnológica de Pereira (UTP), en Colombia y publica sus interesantes reflexiones en la editorial Anthropos. Hay que decir que frente a las frecuentemente excesivas reflexiones filosóficas actuales sus escritos son escuetos, comprensibles y muy s ugerentes. Además es experto en Borges.

\section{Ibíd. p. 9.}

$3 \mathrm{Me}$ refiero a autores poco difundidos en nuestros pagos como Michel de Certau. Pero también a dos corrientes importantes dentro de la investigación sobre imaginarios como: 1 . La vinculada a Gilbert Durand y a sus seguidores como M. Maffesoli, R. Ledrut, G. Balandier que reconocen como fuente originaria a Emile Durkheim, y 2: La importante producción de Manuel A. Baeza (en particular su última obra Mundo real, mundo imaginario social. Teoría y práctica de sociología profunda (Santiago de Chile, RIL, 2008, 542 p.), que recurre a la herencia de Pierre Bourdieu. 